\title{
Morphological characterization of Kenyan native wood ear mushroom [Auricularia auricula (L. ex Hook.) Underw.] and the effect of supplemented millet and sorghum grains in spawn production
}

\author{
Onyango B.O. ${ }^{1^{*}}$, Palapala V.A. ${ }^{2}$, Arama P.F. ${ }^{1}$, Wagai S.O. ${ }^{1}$ and Gichimu B.M. ${ }^{3}$ \\ ${ }^{1}$ Department of Botany and Horticulture, Maseno University, Kenya \\ ${ }^{2}$ Department of Biotechnology, Masinde Muliro University, Kenya \\ ${ }^{3}$ Coffee Research Foundation, Ruiru, Kenya - www.crf.co.ke \\ ${ }^{*}$ Corresponding Author: Email - benboyih@yahoo.com \\ P. O. BOX 1078, KISUMU, KENYA
}

\begin{abstract}
Utilization of mushrooms collected from the wild requires adequate description of useful phenetic features and domestication protocols. This study investigated morphological characters and spawn production procedures of three Kenyan native strains of wood ear mushroom [Auricularia auricula (L. ex Hook.) Underw.]. Nine basidiocarps were selected from collections made in three forest reserves within Kakamega Forest in Western Kenya and morphologically characterized. Mycelia were raised on $2 \%$ malt extract agar and bottle culture technology was used for spawn production. The spawning experiment was arranged in completely randomized design with three replicates. Variations occurred in external basidiocarp features such as color, texture, shape and presence of veined surfaces. Microscopic analysis of internal basidiocarp structures did not reveal significant differences. However, external features of mycelia colonies varied when cultured in malt extract agar. Results from spawn production showed that supplemented millet and sorghum grains can be successfully colonized by mycelia to produce high quality spawn.
\end{abstract}

Keywords: Morphological characterization, Spawn production, Kenya

\section{INTRODUCTION}

Mushrooms of the genus Auricularia commonly known as wood ear mushrooms are edible fungi which have been domesticated for cultivation in different parts of the world (Kirk et al., 2001). Currently, the genus Auricularia is the fourth most important cultivated mushrooms after Agaricus, Lentinula and Pleurotus (Yan et al., 2004). The rapid increase in domestication of this genus from the wild is attributed to its nutritional and medicinal properties (Chang and Miles, 2004). Nutritionally, its basidiocarps contain high protein levels (about 30\% of dry weight) and essential elements such as vitamins, minerals, and polysaccharides (Chang and Miles, 2004). The polysaccharides have been found to have antitumor, antiviral, antibacterial and antiparasitic properties (Ukai et al., 1983; Yang et al., 2002).

In Kenya, mushroom cultivation is not well developed and only exotic species are grown for the hotel industry (Gateri et al., 2004). Palapala et al., (2006) reported the occurrence of three native strains of Auricularia auricula (L. ex Hook.) Underw. in Kakamega Forest in Western Kenya. These native strains are faced by threats of depletion due to over harvesting for consumption by the rural populace. Further, the forest habitats are rapidly being destroyed alongside the germplasm of this fungus to create land for settlement and agriculture (Onyango et al., 2010). Therefore, there is need to develop cultivation methods that will encourage propagation and conservation of this resource protecting it from extinction. The most crucial factor in domesticating wild mushrooms is development of appropriate protocols for spawn production (Oei, 2005; Stamets, 2000). Zervakis et al., (2001) reported that understanding the nutritional and physiological preferences of mushroom mycelia is essential to its domestication. Grain spawns derived from sorghum and millet has successfully been used in the mushroom industry as the 'seed' for bulk inoculation of substrates (Royse et al., 1997; Stamets, 2000; Oei, 2005). Therefore, use of grains such as millet and sorghum for Kenyan native wood ear mushroom spawn production offers the opportunity to utilize local resources in production of edible, protein-rich 
food that will sustain food security for the rural populace (Sanchez et al., 2002).

Members of the genus Auricularia are known to have a wide range of morphological plasticity due to the absence of clearly distinguishing characters (Wong and Wells, 1987). Previous work done on characterization has combined basidiocarp features with characteristics of individual and colonial hyphae (Lowy, 1952; Duncan, 1972). Wong and Wells, (1987) emphasized the need for compatibility and inter-fertility studies in delimiting the members of this genus. More recently, Musngi et al., (2005) used phenotypic differentiations to classify the strains of Auricularia in the Philipines. Currently, no information is available on phenetic characters of wood ear mushroom species that are native to Kenya. A morphological evaluation of these species will provide vital information to characterize them and offer information useful for strain selection during cultivation. In addition, knowledge of the varietal differences can be used as sources of cell lines for researchers and in breeding programmes (Pei-Sheng and Chang, 2004). This information can be applied in mass production of spawns for local cultivation of wood ear mushrooms.

In this study phenotypic analysis of wood ear mushroom samples obtained from Kakamega Forest is been done to provide a better understanding of genetic variations occurring amongst local strains. Before this study, little was known about such variations in Western Kenya and Kakamega Forest in particular.

\section{MATERIALS AND METHODS}

Collection of germplam: Wood ear mushroom germplasm were obtained from three forest reserves of Kakamega Forest in Western Kenya. The forest reserves (Isecheno, Ikuywa and Kisere) are located between longitudes of $34^{\circ} 32^{\prime} \mathrm{O}^{\prime \prime} \mathrm{E}$ and $34^{\circ} 57^{\prime} \mathrm{O} \mathrm{O}^{\prime} \mathrm{W}$ and latitudes of $0^{0} 07^{\prime} 30^{\prime \prime} \mathrm{N}, 0^{0} 10^{\prime} 15^{\prime \prime} \mathrm{S}$ (Wambua, 2004). Fully mature basidocarps were excised from the base using a sharp knife and put in polythene bags. Forty five basidiocarps were collected and assigned accession numbers with respect to the collection site. They were transferred to Masinde Muliro University Biotechnology laboratory where nine representative samples were randomly selected for characterization.

Morphological characterization procedures: The basidiocarps were rehydrated by soaking in water for ten minutes before analyzing their morphology. Qualitative characters such as color, shape, and presence of hymenia were evaluated by eye observation while texture was determined by feeling the back and top surfaces using fingers. For microscopic characters, free hand transverse sections of approximately $0.1 \mathrm{~mm}$ thick were made from rehydrated basidiocarps with the aid of a sharp surgical blade. The sections were immersed in a diluted solution of methyl blue stain and left for 10 minutes. The thinnest sections were selected and placed on glass slides and covered with cover slips. Low power $(\times 40)$ objectives of a standard light microscope were used to observe the sections. Internal basidiocarp zones were recorded by mounted photography. All morphological variations observed were used to develop a descriptor for construction of a dendogram. Numerical values obtained from a descriptor were organized into a matrix and subjected to cluster analysis using $R$ statistical software (Venables et al., 2006). Variables were segregated into numericals and clustered using DAISY (dissimilarity calculation) function (Venables et al., 2006). The clustering algorithm was done by Un-weighted Pair Group Method with Arithmetic mean (UPGMA).

Tissue culture of basidiocarps: The method used for tissue culture of was derived from Weber and Webster, (2006). A laminar flow hood was used to perform the procedure. The lamina flow hood was thoroughly cleansed using cotton swabs soaked in $80 \%$ ethanol after which the fan and UV light were set for 30 minutes to sterilize the working chamber. Petri - plates were prepared by washing thoroughly with ordinary detergents and then autoclaved at 115 ${ }^{\circ} \mathrm{C}$ for 1 hour. Sterilized plates were transferred to an oven for drying at $140{ }^{\circ} \mathrm{C}$ for 30 minutes. Preparation of culture media was done by weighing 25 grams of $2 \%$ malt extract agar which was dissolved in 500 milliliters of distilled water and then sterilized by autoclaving at $115{ }^{\circ} \mathrm{C}$ for 1 hour. The media was poured in sterile Petri dishes and quickly covered using Petri dish lids and allowed to cool and solidify. Re-hydrated basidiocarps were washed thoroughly in sterile water and $5 \%$ sodium hypochlorite. A sharp surgical blade was dipped in $80 \%$ ethanol and flamed until it was red-hot then allowed to cool for 10 seconds. Cleaned mushroom sections were broken lengthwise and sterilized surgical blades used to remove fragments (about $2 \times 2 \mathrm{~mm}^{2}$ ) from inner surfaces of the basidiocarps. Cut fragments were placed in the middle surface of the media, covered with a Petri - dish lid and tightly sealed with a parafilm. Inoculated dishes were then labeled. Distinction of cultures was established depending on collection site using accession numbers previously 
listed. Cultured plates were incubated in dark sterile cabinets for $5-8$ days at $25{ }^{\circ} \mathrm{C}$ to enable mycelia establishment. Sub culturing was done on fresh media to obtain pure cultures. After complete colonization of the Petri dishes, mycelia were exposed from qualitative features of colonies observed by eye included density, texture, presence of aerial hyphae and, type of colony growth and were used for characterization of the species.

Development of grain spawns: Mycelia obtained from tissue culture were used to develop grain spawns. Millet and sorghum grains supplemented with either wheat or rice brans at varying combinations were tested to determine their suitability for spawn production. The grains were soaked in water for four hours to soften before being utilized for spawn production. A total of eight different treatments (300 g each) were used as shown in Table 1. Grains of $100 \%, 80 \%, 50 \%$ and $40 \%$ were obtained by weighing $300 \mathrm{~g}, 240 \mathrm{~g}, 150 \mathrm{~g}$ and $120 \mathrm{~g}$ respectively. Similarly, $20 \%$ bran was obtained by weighing $60 \mathrm{~g}$ of either wheat or rice bran. The weighed grains and brans were then thoroughly mixed by hand. Each grain formulation $(300 \mathrm{~g})$ was mixed with $10 \mathrm{~g}$ of $\mathrm{CaCO}_{3}$ powder to regulate their $\mathrm{pH}$. To produce grain spawn of $50 \%$ moisture level, water was added at a rate of 200 milliliters per $300 \mathrm{~g}$ of formulation. Grain combinations were put in $500 \mathrm{ml}$ heat resistant glass bottles and autoclaved for 1 hour at $121^{\circ} \mathrm{C}$. Bottles were allowed to cool in a sterile lamina flow hood after shaking them to loosen and evenly distribute wet and dry grains. Flame sterilized surgical blades were used to cut out $(1 \times 1 \mathrm{~cm})$ square pieces of agar covered mycelium. The agar pieces were carefully transferred to upper surfaces of prepared grains. For each grain combination, inoculation was replicated three times. Inoculated grain bottles were tightly secured using moist cotton wool and covered with sterile aluminum foil and bottle lids. They were kept in dark sterile cabinets at ambient room temperatures for 7- 20 days until they were fully colonized. Spawn production experiments were laid out in a Completely Randomized Design (CRD) and replicated three times. Data collected were subjected to Analysis of Variance (ANOVA) at $5 \%$ level of significance using the SAS version 9.1 (SAS Institute, 2005).

Table 1. Grain and supplement formulations for spawning

\begin{tabular}{|l|l|}
\hline & Grains and supplement formulations \\
\hline 1 & $40 \%$ millet $+40 \%$ sorghum $+20 \%$ wheat bran \\
\hline 2 & $80 \%$ millet $+20 \%$ wheat bran \\
\hline 3 & $80 \%$ sorghum $+20 \%$ wheat bran \\
\hline 4 & $40 \%$ millet $+40 \%$ sorghum $+20 \%$ rice bran \\
\hline 5 & $80 \%$ millet $+20 \%$ rice bran \\
\hline 6 & $80 \%$ sorghum $+20 \%$ rice bran \\
\hline 7 & $50 \%$ millet $+50 \%$ sorghum \\
\hline 8 & $100 \%$ millet \\
\hline
\end{tabular}

\section{RESULTS AND DISCUSSION}

Morphological characterization: Nine basidiocarps bearing accession numbers Isc006, Iky013, Kis017, Isc014, Iky023, Kis003, Isc019, Iky021 and Kis008 were selected for characterization. Strain identification was based on basidiocarp morphology and structure of mycelia colonies as shown on Table 2. Three main basidiocarp colors were observed. These included yellow brown (accessions Isc006, Iky013, Kis017); brown (accessions Isc014, Iky023, Kis003); and dark brown (accessions Isc019, Iky021, and Kis008). However, some mushrooms bore lighter or darker sheds of these colors and were grouped together with the predominant color. Sobal et al., (2007) reported that the species of Auricularia auricula (L. ex Hook.) have mainly brown and dark brown basidiocarps even though lighter basidiocarps have been observed. With regard to basidiocarp shapes, there occurred significant variations ranging from auriform, discoid, and campanulate. Most of yellow brown strains were ear shaped, majority of brown strains were discoid and campanulate while a good number of dark brown strains were flattened. According to Wong and Wells (1987), wood ear mushrooms are mainly ear-shaped but bell shaped and flattened types have been encountered. There also occurred variations in the texture of the basidiocarps. Yellow brown basidiocarps were softest exhibiting gelatinous feels. Brown strains were rubbery while the dark brown had tougher feels making them leathery. These variations were 
consistent for collections from the different forest reserves.

Raitvir (1971) indicated that the presence or absence of the medulla in the internal anatomy of the basidiocarp was of value in delimiting the species. However, microscopic analysis of basidiocarp sections in this study did not reveal major differences between the three strains since the medulla was absent in all the strains. Absence of the medulla was a clear indication that all the studied strains belonged to the species Auricularia auricula according to Lowy's (1952) system of classifying this genus. The outermost part had a compact mass of tissue called the zona compacta. Centrally placed was a single large region of loose hyphae called the zona laxa. The hyphae of this region appeared loosely arranged forming a clearly distinct band from other parts. Occurring above and below the zona laxa were two layers known as zona subcompacta. The lower side bore abhymenial hairs making the surface to appear rough. This characteristic was consistent to all accessions. However, a good number of accessions Isc019, Iky021, and Kis008 lacked the hairs and had completely smooth undersides. Traditionally, Auricularia auricula (L. ex Hook.) mushroom species have been delimited according to basidiocarp characteristics (Lowy, 1951). However recent work on this species indicates that morphological plasticity of the basidiocarp has been inconclusive in establishing a stable characterization (Pei-Sheng and Chang, 2004). The findings of this study showed that mycelia colonies of accessions Isc019, Isc006, Kis003, Kis008, Iky023 and Iky013 were white and cottony, with abundant aerial hyphae while accessions Isc014, Kis017 and Iky021 produced offwhite, velvety and low-density mycelia with scarce aerial hyphae. As outlined by Sobal et al., (2007) mycelia colony morphology traits such as color, density, texture and aerial hyphae are crucial in distinguishing between Auricularia species. However, Buswell and Chang, (1993) reported that fungal groups with genetically uniform populations can exhibit striking phenotypic variability. It may be possible that the three strains evaluated were genetically similar even though they showed marked phenotypic variability in the mycelia colony traits as they grew on malt extract agar.

The identification used in this study may not be conclusive in differentiation of the native wood ear mushroom strains since morphological characteristics may result from environmental factors such as temperature, sunlight, humidity, and some physical factors that vary from time to time and from one place to the other. Further analysis using molecular markers is necessary to clearly distinguish between the strains.

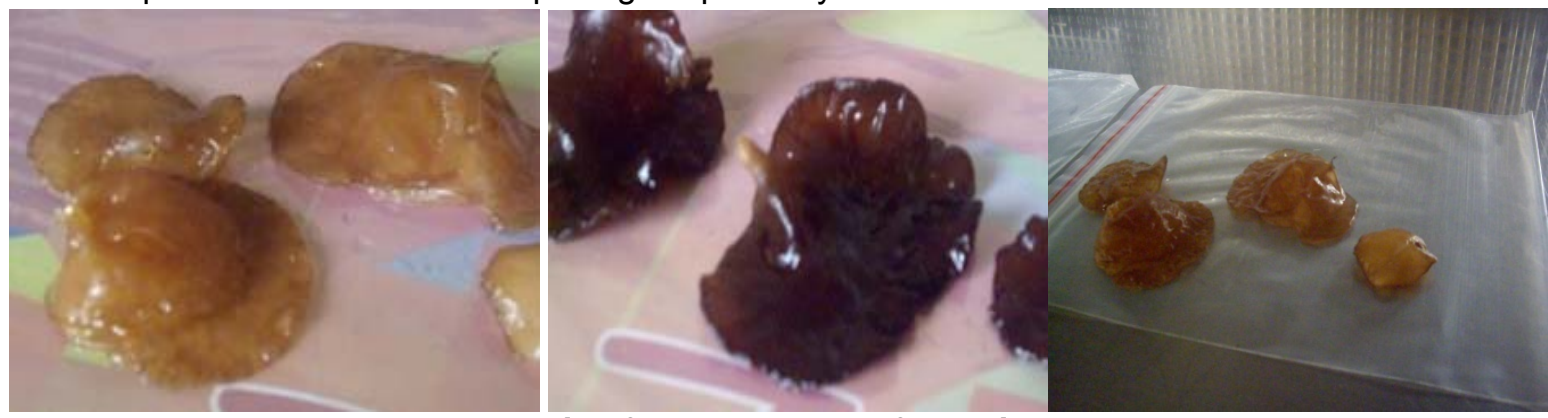

Plate 1: Wood ear mushroom strains from Kakamega forest in western Kenya.

Table 2: Variation in morphological characters in the nine wood ear mushroom accessions

\begin{tabular}{|c|c|c|c|c|c|c|c|c|c|c|}
\hline \multirow[t]{2}{*}{$\begin{array}{l}\text { Acc. } \\
\text { No. }\end{array}$} & \multicolumn{3}{|c|}{ External structure of basidocarp } & \multicolumn{3}{|c|}{$\begin{array}{l}\text { Internal structure of } \\
\text { basidiocarp }\end{array}$} & \multicolumn{4}{|c|}{ Mycelia structure } \\
\hline & Color & Shape & Texture & Medulla & Zones & Hymen & Color & Density & Type & Aerial \\
\hline Isc019 & DB & Fattened & Leathery & Absent & C-S-L & Present & White & High & Cottony & Abundant \\
\hline Isc014 & $\mathrm{BR}$ & Discoid & Rubbery & Absent & C-S-L & Present & Offwhite & Low & Velvety & Scarce \\
\hline Isc006 & YB & Auriform & Gelatinous & Absent & C-S-L & Present & White & High & Cottony & Abundant \\
\hline Kis003 & BR & Discoid & Rubbery & Absent & C-S-L & Present & White & High & Cottony & Abundant \\
\hline Kis017 & YB & Auriform & Gelatinous & Absent & C-S-L & Present & Offwhite & Low & Velvety & Scarce \\
\hline Kis008 & DB & Fattened & Leathery & Absent & C-S-L & Present & White & High & Cottony & Abundant \\
\hline lky023 & $\mathrm{BR}$ & Discoid & Rubbery & Absent & C-S-L & Present & White & High & Cottony & Abundant \\
\hline lky021 & DB & Fattened & Leathery & Absent & C-S-L & Present & Offwhite & Low & Velvety & Scarce \\
\hline Iky013 & YB & Auriform & Gelatinous & Absent & C-S-L & Present & White & High & Cottony & Abundant \\
\hline
\end{tabular}

NB: DB-Dark brown; BR-Brown; YB-Yellow brown; Isc-Isecheno; Kis-Kisere; Iky-Ikuywa

C-S-L= Zona compacta-Zona subcompact-Zona laxa 
Agric. Biol. J. N. Am., 2011, 2(3): 407-414

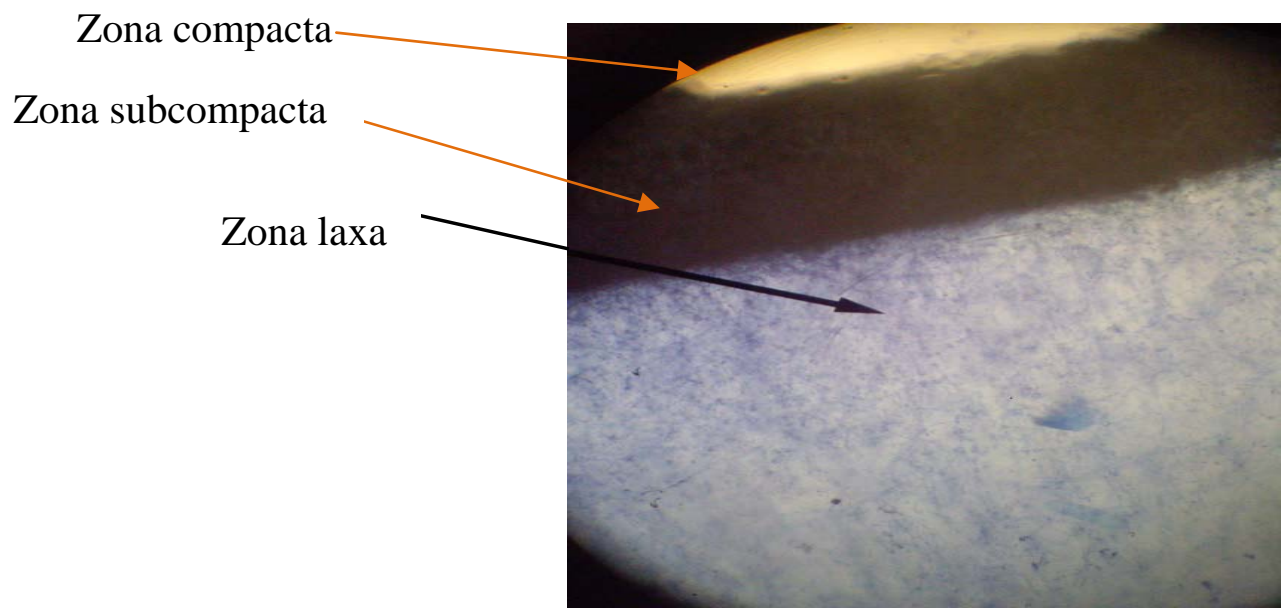

Plate 2: Vertical section of the wood ear mushrooms revealing the internal zones $(\times 40)$

The phenetic data obtained were used to produce a dendogram which revealed a significant diversity amongst the nine accessions studied (Figure 1). A dissimilarity coefficient analysis showed two morphological clusters at an index of 0.38. Three (dark brown strains) out of nine accessions were grouped together (shown by $\mathrm{A}$ on the faint line) indicating that they were statistically indistinguishable using the morphological data analyzed. The other six accessions separated at a narrower genetic diversity (shown by B on the faint line). These results demonstrated a greater diversity between the dark brown strain and the two other strains and concur with the findings of Chang and Lin (1997) that some wood ear mushroom strains have a narrow genetic background. Sobal et al., (2007) attributed such narrow variations in the morphology of wood ear mushrooms to the environmental conditions in which they grew. Remarkable about this study is that morphological variations sufficiently produced a dichotomy between the nine accessions revealing three distinct groups at low dissimilarity indices. Though it is mostly appropriate to distinguish between mushroom strains using molecular data (Pei-Sheng and Chang, 2004) it was clear that the morphological features studied produced variations within otherwise similar individuals. Therefore, a conceivable evolutionary root of Kenyan native wood ears may be revealed by the cluster analysis. It is however possible that some genetic differences might have gone unnoticed because morphological markers are usually limited in determining genetic diversity. In addition, the samples used in this study were quite few.

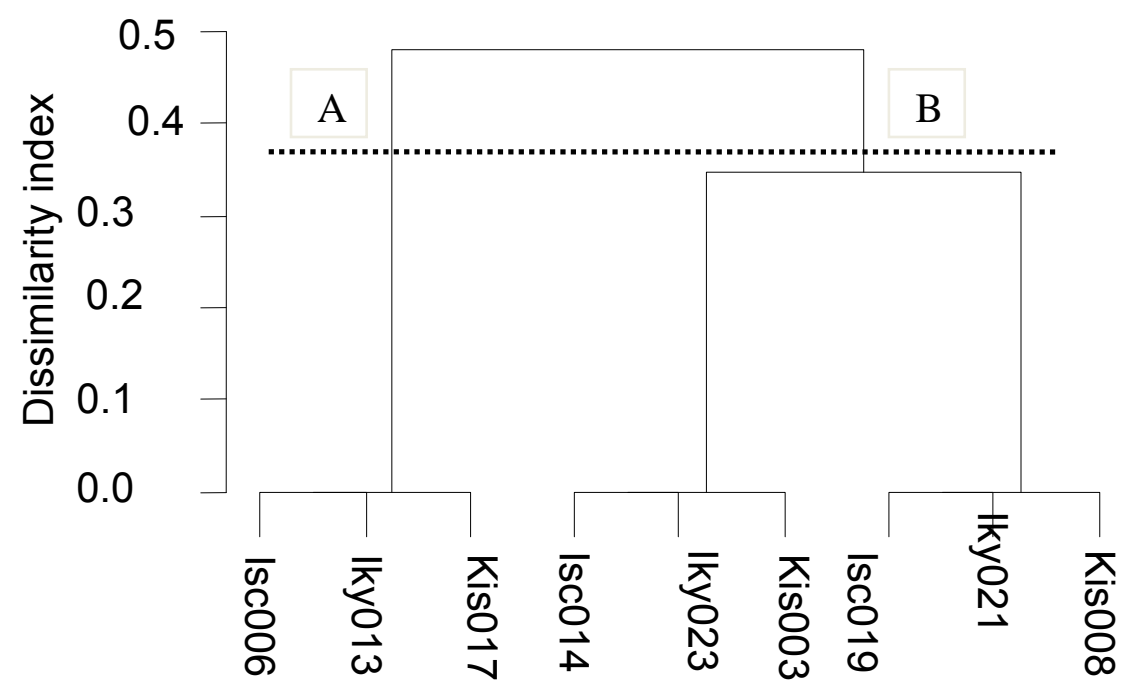

Fig 1. Cluster dendogram illustrating morphological diversity between nine wood ear mushroom accessions. The scale shows dissimilarity distance between the accessions. The faint line shows confidence limits of $95 \%$ giving a dissimilarity index of 0.38 . NB: Isc-Isecheno; Kis-Kisere; Iky-Ikuywa (Forest reserves) 
Spawn production: After bottles containing different grain combinations were inoculated, it took between 3-4 days for mycelia to be established as shown in Plate 2. Mycelia rapidly progressed down the formulations completely ramifying them at different rates. The grain combination of $40 \%$ millet $+40 \%$ sorghum with $20 \%$ wheat bran gave significantly $(p<0.05)$ the fastest rate of colonization of 10 days. This was followed by $80 \%$ millet and $20 \%$ wheat bran which lasted 11 days. The slowest rate $(p<0.05)$ of colonization was witnessed in non supplemented millet which took 14 days. Rapid mycelia growth observed in this study may be attributed to a greater food reservoir in large sorghum grains, whereas the smaller millet grains provided a greater number of inoculation points. According to Narain et al. (2008) high rates of colonization may be attributed to mycelia getting the most suitable ratio of mixture with a high reservoir of energy and all the nutritional ingredients such as carbon, nitrogen, lipids and minerals. Vigorous substrate colonization by the mycelium during spawn run is desirable because it reduces mushroom cropping time and may allow mycelium to outgrow competitors in the substrate (Royse, 2007).

The influence of supplements used in this study as nutritional additives was found to be very high. This was confirmed by rapid mycelia growth witnessed in all supplemented formulations as shown in Table 2. According to Royse (1997), bran supplementation provides a protein rich medium which can increase rate of mycelia growth two-fold. Conversely, nonsupplemented grains gave significantly the slowest $(p<0.05)$ growth rates as observed in $100 \%$ millet and $50 \%$ millet $+50 \%$ sorghum both lasting 14 days.
It was therefore clear that supplementation with either wheat or rice brans increased the speed of mycelia growth. Additionally, compactness or poor aeration of the grains may have resulted in inefficient utilization of nutrients thereby slowing mycelia growth rate in non-supplemented grains. Comparison between the supplements showed that wheat bran was significantly better $(p<0.05)$ than rice bran regarding their influence on mycelia growth. All the grains supplemented with wheat bran took a shorter time to fully colonize compared to those combined with rice bran. Although nutritional evaluation of the brans used was not done, it is highly probable that the wheat bran used in this study had a higher protein content increasing the nitrogen level in the grains. Uhart et al., (2008) analyzed the nutritional values of different supplements and concluded that wheat bran contained better quality nutrients that increase the rate of mycelia growth. Shashireka et al. (2005) attributed enhanced performance of mycelia on availability of several amino acids and protease as well as transaminase enzyme activities on wheat bran. Another factor that may have influenced the rate of mycelia growth is quality of the inoculants used and aeration of the grains. Stamets (2000) recommended dense and thick mycelia to be used for inoculation of grains for spawn formation. Since the portion of inoculants obtained from the yellow brown strain used to colonize the grain spawns was dense, it progressed with vitality colonizing the grains at a faster rate.

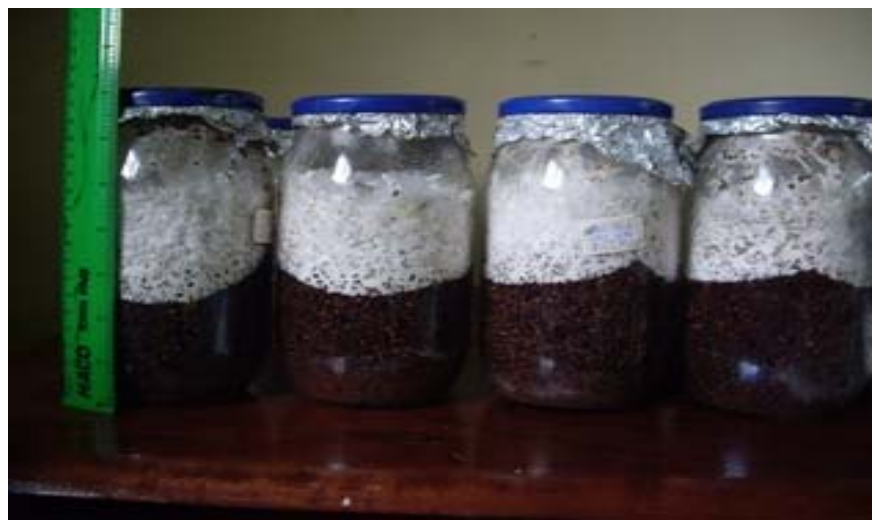

Plate 2: Wood ear mushroom mycelia colonizing supplemented millet and sorghum grains 
Agric. Biol. J. N. Am., 2011, 2(3): 407-414

Table 2. Effects of grain-supplement combinations on days to complete spawn run (days)

\begin{tabular}{|c|c|c|c|}
\hline \multirow{2}{*}{ Grain Formulations } & \multicolumn{3}{|c|}{ Mushroom strains } \\
\hline & $\begin{array}{l}\text { Yellow } \\
\text { brown }\end{array}$ & Brown & $\begin{array}{l}\text { Dark } \\
\text { brown }\end{array}$ \\
\hline $40 \%$ millet $+40 \%$ sorghum $+20 \%$ wheat bran & $10.0^{\text {def }}$ & $12.0^{\mathrm{d}}$ & $13.0^{\mathrm{ef}}$ \\
\hline $80 \%$ millet $+20 \%$ wheat bran & $10.6^{\text {cdef }}$ & $12.6^{\text {cd }}$ & $13.6^{\mathrm{e}}$ \\
\hline $80 \%$ sorghum $+20 \%$ wheat bran & $11.0^{\text {bcde }}$ & $12.6^{\mathrm{cd}}$ & $13.3^{\mathrm{ef}}$ \\
\hline $80 \%$ millet $+20 \%$ rice bran & $11.6^{\mathrm{bcd}}$ & $13.7^{\mathrm{abcd}}$ & $15.6^{\mathrm{abc}}$ \\
\hline $80 \%$ sorghum $+20 \%$ rice bran & $12.0^{\mathrm{abc}}$ & $13.3^{\mathrm{abcd}}$ & $15.3^{\mathrm{abcc}}$ \\
\hline $40 \%$ Millet $+40 \%$ sorghum $+20 \%$ rice bran & $12.6^{\mathrm{ab}}$ & $14.0^{\mathrm{abc}}$ & $15.3^{\text {abcc }}$ \\
\hline $50 \%$ millet $+50 \%$ sorghum & $13.6^{\mathrm{a}}$ & $14.3^{\mathrm{ab}}$ & $16.0^{\mathrm{ab}}$ \\
\hline $100 \%$ millet & $13.6^{\mathrm{a}}$ & $14.6^{\mathrm{a}}$ & $16.3^{\mathrm{a}}$ \\
\hline Means per strain & 11.9 & 13.4 & 14.8 \\
\hline CV (\%) & \multicolumn{3}{|c|}{10.1} \\
\hline LSD $_{0.05}$ & \multicolumn{2}{|c|}{1.7} & \\
\hline
\end{tabular}

Note: Means followed by the same letter along the same column are not significantly different

\section{CONCLUSION}

Three strains of Auricularia auricula (L. ex Hook.) Underw. mushrooms native to Kenya were successfully characterized using morphological characters. However, further differentiation using morphological markers was recommended. It was evident that wheat bran supplementation of millet and sorghum grains has a high potential for utilization for spawn production of Kenyan native wood ear mushrooms. An equal mixture of millet and sorghum supplemented with wheat bran produced the best results and were recommended for spawn production. Apparently, these locally available grains are rich in nutrients which can be utilized by mushroom mycelium to aid in spawn production.

\section{ACKNOWLEDGEMENT}

This study was sponsored by the African Institute for Capacity Development (AICAD). Masinde Muliro University of Science and Technology is acknowledged for providing laboratory space, equipments and technical assistance. Thanks are due to Dr. George Odhiambo of Department of Botany and Horticulture, Maseno University, for his valuable assistance in data analysis. The authors are also greatly indebted to Mr. Wycliffe Masinde of Kakamega Environmental Education Program (KEEP) who provided guidance to the sites of germplasm collection.

\section{REFERENCES}

Buswell, J. A. and Chang S. (1993). Edible mushrooms; attributes and application in genetics and breeding of edible mushrooms; Gordon and Breach Science, Amsterdam. p 297-324

Chang S-T and Lin S. F. (1997). Mushroom genetics and breeding; China Agricultural Press : $\mathrm{p}$ 70-97.

Chang S-T and Miles P.G. (2004). Cultivation, Nutritional Value, Medicinal Effect and Environmental Impact of Mushrooms $2^{\text {nd }}$ Ednt; (CRC press) Bora Raton London New York Washington DC: $p$ 35-40.

Duncan, E. G. (1972). Microevolution in Auricularia polytricha. Mycologia 64: 394-404.

Gateri , M. W., Muriuki, A. W and Waiganjo M.W. (2004). Cultivation and commercialization of edible mushrooms in Kenya; A review of prospects and challenges of smallholder production. National Horticulture Research Center, Thika; Kenya: 1-7.

Lowy, B. (1952). The genus Auriculaia; Mycologia 44:656692.

Martinez-Carrera, D., Bonialla, M., Martinez, W., Sobal, M., Aguilar, A. and Gonzalez, P. (2002). Characterization and cultivation of wild Agaricus species from Mexico; Micologia Applicada Internationale. 13:9-24.

Musngi, R. B., Abella, E.A., Lalap, A.L. and Reyes, R.G. (2005). Four species of wild Auricularia in Central Luzon, Philippines as sources of cell lines for researchers and mushroom growers. Journal of Agricultural Technology 1(2): 279-299.

Narain, R., Sahu, R. K., Kumar, S., Garg, S. K., Singh, C. S. and Kanaujia, R.S. (2008). Influence of different nitrogen rich supplements during cultivation of Pleurotus florida on corn cobs substrate; Environment. 13:67 -71.

Oei, P. (2005). Small scale mushroom cultivation; Agrodok. 40:65-66. 
Onyango, B., Arama, P., Palapala, V., Wagai, S. and Gichimu, B. M. (2010). Suitability of selected supplemented substrates for cultivation of Kenyan native wood ear mushrooms (Auricularia auricula). American Journal of Food and Technology. 10: 1-9

Palapala, V., Miheso F. P. and Nandi, O. (2006). Cultivation potential of indigenous species of African wood ear mushrooms. Paper presented at Masinde Muliro University, Kenya: p 1-21

Pei-Sheng, Y. and Chang X. (2004). RAPD molecular differentiation of the cultivated strains of the mushrooms Auricularia auricula and A. polytricha; IMIST-CNRS :73-92.

Raitvir, A. (1971). The tremellaceous fungi of the Far East; Plants and animals of Soviet Far East. $5^{\text {th }}$ Edt. Parmatsi, Valgus tallum : p $84-154$.

Royse, D. J. (1997). Specialty Mushrooms and their Cultivation; Horticulture Review 19:59-97.

SAS Institute. (2005). SAS users guide: SAS/STAT, Version 9.1. Cary (USA) SAS Institute.

Sanchez, J. E., Royse, D. J. and Hernandez G. (2002). Development of non composted substrates for production of Agaricus bisporus. Publ. Sanchez J. E., Huerta G., Montiel; Mushroom biology and mushroom products. Impresus Jupiter Cuernavaca : p 265 - 270

Shashireka, M. N., Rajrathnan, S. and Bano, Z. (2005). Effects of supplementing rice bran substrate with cotton seeds on analytical characterization of mushroom Pleurotus florida.; Food Chemistry. 92:255 259

Sobal, M., Martinez-Carrera, D., Morales, P. and Roussos, S. (2007). Classical characterization of mushroom genetic resource from temperate and tropical regions of Mexico; Mycologia Aplicada International, Berkeley (USA). 19:15-23.
Stamets, P. (2000). Growing gourmet and medicinal mushrooms; $3^{\text {rd }}$ edtn. Ten speed press. BerkeleyToronto: $p$ 153-167.

Uhart, M., Piscera, J.M., Albert, E. (2008). Utilization of new naturally occurring strains and supplementation to improve biological efficiency of the edible mushroom Agrocybe cylindracea; Journal of Indian Microbiology and Biotechnology. 35:595 -602.

Ukai, S., Kiho T., Hara, C., Kuruma, I. and Tanaka, Y. (1983). Polysaccharides in fungi: Anti-inflammatory effect of the polysaccharides from the fruit bodies of several fungi. Journal of Pharmacobiology 6:983-90.

Venables, W. N., Smith, D. N., and R Development Core Team. (2006). An introduction to R: A programming environment for data analysis and graphics. Version 2.5.1. <http://www.r-project.org>

Wambua, J. (2004). Mushroom cultivation in Kenya; Mushroom growers handbook. Part III. O. U. Press. 1: p 197-203.

Weber, R.W.S and Webster, J. (2006). Teaching techniques for mycology: patterns of basidiospore and fruiting body germination in Auricularia (Heterobasidomycetes); Mycologist. 20:105-108.

Wong, G. and Wells, K. (1987). Comparative morphology, compatibility and infertility of Auricularia cornea, $A$. polytricha and A. tenuis; Mycologia 79:847-856.

Yang, N., Liang, Y., Xiang, Y., Zhang, Y., Sun, H. and Wang, DC (2002). Crystallization and preliminary crystallographic studies of an antiitumour lectin from the edible mushroom Agrocybe aegerita. Protein Peptide Letters 12: 705-707.

Zervakis, G.A., Philippoussis, A. and Diamantopoulou, P. (2001). Bioconversion of agricultural lignocellulosic wastes through the cultivation of the edible mushrooms Agrocybe aegerita, Volvariella volvacea and Pleurotus sp; World Journal of Microbiology and Biotechnology 17:191-200. 